\title{
Umbilical cord clamping in term piglets: A useful model to study perinatal asphyxia?
}

\author{
A.J. van Dijk ${ }^{\text {a,* }}$, J.P.A.M. van Loon ${ }^{\text {b }}$, M.A.M. Taverne ${ }^{c}$, F.H. Jonker ${ }^{c}$ \\ a Department of Veterinary Pharmacology, Pharmacy and Toxicology, Faculty of Veterinary Medicine, \\ Utrecht University, PO Box 80152, 3508 TD Utrecht, The Netherlands \\ ${ }^{\mathrm{b}}$ Department of Equine Sciences, Faculty of Veterinary Medicine, Utrecht University, \\ PO Box 80153, 3508 TD Utrecht, The Netherlands \\ ${ }^{\mathrm{c}}$ Department of Farm Animal Health, Section of Foetal and Perinatal Biology, \\ Faculty of Veterinary Medicine, Utrecht University, PO Box 80151, 3584 CL Utrecht, The Netherlands
}

Received 12 December 2007; received in revised form 6 April 2008; accepted 21 April 2008

\begin{abstract}
Perinatal asphyxia results in tissue and cellular changes during the reperfusion period and clinical signs like perinatal mortality and decreased vitality at birth in newborn piglets. This study aimed to develop and validate a model of birth asphyxia, mimicking the evolvement of birth asphyxia in natural farrowings by conducting umbilical cord clamping (UCC) in term piglets during caesarean sections under general anaesthesia. In total 23 piglets were subjected to 5-8 min of UCC and 24 piglets served as controls. Acid-base balance values and heart rates measured before UCC remained fairly constant throughout the surgical procedure, indicating nearly identical starting conditions of piglets within and between litters. UCC resulted in a significant, mild, mixed respiratory-metabolic acidosis $\left(\mathrm{pH} 7.22, p \mathrm{CO}_{2} 9.8 \mathrm{kPa}, \mathrm{BE}_{\text {ecf }} 2 \mathrm{mmol} / \mathrm{L}\right.$, lactate $6.5 \mathrm{mmol} / \mathrm{L}$; controls: $\mathrm{pH} 7.31, p \mathrm{CO}_{2} 8.5 \mathrm{kPa}, \mathrm{BE}_{\text {ecf }} 5 \mathrm{mmol} / \mathrm{L}$, lactate $4 \mathrm{mmol} / \mathrm{L}$ ) at $10 \mathrm{~min}$ after birth (defined as simultaneous cutting of the umbilical cord and removal of a plastic bag that had been placed over the head to avoid air intake). Heart rates were significantly decreased during UCC (range: $83-107$ beats/min versus $128-134$ beats/ min in controls). Rectal temperatures and changes in body weight until $72 \mathrm{~h}$ of life were not affected by UCC. Interestingly, four control and seven clamped piglets did not survive as no independent respiration could be attained. Birth weights and duration of UCC of these piglets did not differ significantly from those in surviving control and clamped piglets. In conclusion the mixed respiratory-metabolic acidosis arising in the surviving clamped piglets is not as severe as can be expected in highly asphyxiated, vaginally delivered newborn piglets. Repeatability of the model is compromised by considerable variation in the individual response to UCC.
\end{abstract}

(C) 2008 Elsevier Inc. All rights reserved.

Keywords: Perinatal asphyxia; Newborn piglets; Umbilical cord clamping; Acid-base balance values; Heart rates

\section{Introduction}

Besides the directly visible adverse effects of perinatal asphyxia, like high perinatal mortality rates

\footnotetext{
* Corresponding author. Tel.: +31 30 2533570/5458; fax: +31302534125 .

E-mail address: a.j.vandijk@uu.nl (A.J.van Dijk).
}

[1] and reduced postnatal vitality [2,3] observed in piglets born under farm conditions, numerous detrimental changes at tissue and cellular level arise in the post-ischemic reperfusion period [4]. For example, in newborn piglets that have been subjected to hypoxiaischemia in laboratory experiments, modified expression patterns of stress related proteins have been demonstrated in brain, heart and intestines [5-7]. Apparently this attributes to clinical signs, varying from 
delivery of less viable piglets [1,2] and reduced early postnatal vitality $[2,3]$ to decreased growth and survival rates until the age of 10 days [3].

The evolvement of neurological deficits due to brain damage in surviving human neonates [8] has urged research to focus on strategies to prevent the severe, adverse outcome arising from birth asphyxia. Newborn (1-3-day-old) piglets are commonly used as experimental animal in these studies [9]. The various methods applied to induce hypoxia and/or ischemia include, among others, reduction of the fraction of inspired oxygen, either by placing newborn piglets in a hypoxia chamber with a reduced ambient oxygen tension [7] or by decreasing the inspiratory oxygen percentage in mechanically ventilated piglets [10]. The latter method has also been conducted with simultaneous occlusion of both carotid arteries [11,12].

Apart from the fact that in some models only the brain is exposed to a significant degree of hypoxia, all these models have in common that any relation with the natural expulsion of piglets and the concomitant risk factors for the evolvement of birth asphyxia, like occlusion, damage or even rupture of the umbilical cord [3], is lacking. This seriously limits the use of such models to study (pharmacological) intervention methods aimed at reducing or preventing adverse effects arising from birth asphyxia in piglets kept under normal farm conditions.

As both the incidence and the degree of birth asphyxia experienced in newborn piglets during birth are highly variable and rather unpredictable $[13,14]$, Herpin et al. [13] developed a model of acute asphyxia by providing anteriorly presented piglets with a facemask to prevent breathing during the first $4 \mathrm{~min}$ of life. Although a quick recovery from the resulting respiratory acidosis was observed, plasma lactate values of the asphyxiated piglets remained significantly elevated during the first $75 \mathrm{~min}$ of life [13]. However, a major disadvantage of this model is that the hypoxia that the newborn piglets are exposed to might well be superimposed on a more or less severe degree of acidosis, already experienced during the expulsive stage of farrowing [15].

To design a model of asphyxia, which is in more close agreement with the development of birth asphyxia that occurs during vaginal deliveries, the main causes of birth asphyxia have to be considered.

According to Randall [1] and Christianson [16], the loss of umbilical cord functionality is an inevitable risk factor in the evolvement of birth asphyxia and thus perinatal mortality. This is emphasized by the finding that over $90 \%$ of the intra-partum stillborn piglets are born with a ruptured umbilical cord [17]. Mota-Rojas et al. [18] provided indirect evidence for the vital importance of the umbilical cord by demonstrating that administration of oxytocin resulted in a significantly higher percentage of stillbirths with haemorrhage and rupture of the umbilical cord. In piglets born alive but with broken umbilical cords, significantly lower $\mathrm{pH}$ values at birth have been found [15]. Furthermore, a more pronounced mixed respiratory-metabolic acidosis is observed in umbilical artery blood of liveborn piglets towards the end of the expulsive stage of farrowing [15]. These acid-base balance values are, however, still not comparable to those found in asphyxiated piglets [3] which implies that additional, deteriorating factors play a role in affecting the condition of the piglet at birth.

The aim of the study presented here was to develop and validate a model of birth asphyxia that mimics the evolvement of birth asphyxia in natural farrowings, by exposing term piglets to several minutes of umbilical cord clamping during caesarean sections in late pregnant sows. Such a standardised model would allow controlled studies of (non-)pharmacological intervention methods for reduction or prevention of the adverse effects resulting from birth asphyxia in newborn piglets. Outcome parameters of this model included analysis of acid-base balance values in blood samples from the umbilical vein and artery, measurement of heart rate and rectal temperatures, and evaluation of daily changes in body weight during the first $72 \mathrm{~h}$ of life.

\section{Materials and methods}

The experiment was approved by the Ethical Committee of the Veterinary Faculty of Utrecht University (the Netherlands).

\subsection{Animals and experimental procedures}

For this study, four late pregnant sows (gestational age 112-113 days) of second (three animals) and third (one animal) parity of the Topigs 20 breed were used. The sows were accommodated at the experimental pig farm The Tolakker, Faculty of Veterinary Medicine, Utrecht. Prior to surgery animals were weighed and fasted overnight but had ad libitum access to water. On the day of surgery, animals were transported to the surgical unit. Upon their arrival in this unit, sows were allowed to accommodate for $1 \mathrm{~h}$ before intramuscular premedication with azaperone $(5.5 \mathrm{mg} / \mathrm{kg})\left(\right.$ Stresnil $^{\circledR}$, Janssen-Cilag, Tilburg, the Netherlands), ketamine $\left(2 \mathrm{mg} / \mathrm{kg}\right.$ ) (Narketan ${ }^{\circledR}$, Vétoquinol B.V., 's Hertogenbosch, the Netherlands) and midazolam $(0.03 \mathrm{mg} / \mathrm{kg})$ 
(Dormicum ${ }^{\circledR}$, Roche, Woerden, the Netherlands) was performed. Induction of anaesthesia was conducted with intravenous ketamine $(3 \mathrm{mg} / \mathrm{kg})$ and midazolam $(0.04 \mathrm{mg} / \mathrm{kg})$, administered via a 16 -gauge catheter (Intraflon ${ }^{\circledR}$, Vicon, Valkenswaard, the Netherlands), placed in an auricular vein. Upon induction of anaesthesia, the sow was placed on the operating table in right lateral recumbency on a heat pad (to maintain body temperature), and the trachea was intubated with a silicone-cuffed tube $\left(14 \mathrm{~mm}\right.$ i.d., Cook ${ }^{\mathbb{R}}$, Chicago, USA). Anaesthesia was maintained with isoflurane (1.6-1.8\% end tidal (E.T.) in oxygen) (Isoflo ${ }^{\circledR}$, AST Pharma, Oudewater, the Netherlands). Intermittent positive pressure ventilation was applied when E.T. $\mathrm{CO}_{2}$ increased to $8 \%$ or higher or when apnoea occurred. Throughout the surgical procedure, sows were continuously monitored by means of clinical assessment of the depth of anaesthesia. Furthermore, heart rate, respiratory rate, E.T. $\mathrm{CO}_{2}$, E.T. isoflurane, arterial oxygen saturation and rectal temperature of the sow were monitored and repeated arterial blood sampling from the auricular artery was performed to monitor the maternal acid-base balance and blood gases $\left(\mathrm{PaCO}_{2}, \mathrm{PaO}_{2}, \mathrm{HCO}_{3}{ }^{-}\right.$, and $\mathrm{BE}_{\mathrm{ecf}}$, lactate). Lactated ringer (Baxter, Utrecht, the Netherlands) was infused intravenously at a dose rate of $5 \mathrm{~mL} / \mathrm{kg} / \mathrm{h}$ in all sows.

As it was aimed to minimise the influence of isoflurane anaesthesia on the unborn piglets, general anaesthesia of the sow was kept at a light but sufficient level. Therefore it was decided to perform additional local infiltration anaesthesia to preclude any local pain sensation from the flank laparotomy in the sow. Before local infiltration anaesthesia with bupivacaïnehydrochloride-monohydrate (Marcaine $^{\circledR}, 2.5 \mathrm{mg} / \mathrm{mL}$, AstraZeneca, Zoetermeer, the Netherlands), the surgical area was shaved and disinfected.

A left lateral laparotomy was performed and a fetal compartment just beneath the abdominal incision was exteriorised and positioned on the covered abdomen of the sow. The fetal compartment was subsequently incised to carefully remove the piglet while avoiding traction on the umbilical cord. Care was taken to only exteriorise one or two fetal compartments at a time to minimise disturbance of uterine blood flow.

To avoid triggers for the onset of respiration in the exteriorised piglets, each piglet was positioned on the covered abdomen of the sow under a $150-\mathrm{W}$ infrared lamp and a plastic bag was immediately placed over the head to avoid air intake. Fig. 1 provides a detailed description of the protocol applied to individual piglets from this moment onwards. After measuring the reference heart rate (HR) by counting of the umbilical artery pulsations during $15 \mathrm{~s}$, a waiting period (WP) started or an umbilical cord clamping period (UCC) took place by double clamping of the umbilical cord. Both the WP and the UCC period were finished by removing the bag and simultaneous cutting of the umbilical cord, together defined as 'birth' of the piglet.

Preliminary data had shown that UCC of on average $4.3 \mathrm{~min}$ caused no significant effects on acid-base balance values at 10 and $30 \mathrm{~min}$ of life. Additionally, Randall [19] has shown that after a first episode with profound bradycardia due to UCC in utero, a second bradycardia episode evolved that inevitably resulted in death of the piglet. As we aimed to study postnatal effects of birth asphyxia in surviving piglets, the HR was measured every minute in the same way as described above during the WP and the UCC period. UCC was ceased as soon as a second episode with bradycardia appeared to develop. As a result individual variation in the duration of UCC ranged from 5.0 to $8.0 \mathrm{~min}$ (average $7.0 \mathrm{~min}$ ). Duration of the WP in control (non-clamped) piglets was adjusted to that of the UCC period of the preceding piglet.

To avoid possible damage of the umbilical vein (UV) and artery (UA) during the WP, reference blood samples (RBS) from UV and UA in control piglets were collected just prior to birth, whereas in clamped piglets RBS were collected from UV and UA between the two clamps, within 2 min after starting UCC. Consequently, RBS from control and clamped piglets were collected at different time points prior to birth. Additionally, in clamped piglets a postclamping blood sample (PostBS) was collected from the UA (between the proximal clamp and the umbilicus) at birth.

Immediately upon birth (defined as removal of the bag and simultaneous cutting of the umbilical cord), piglets were held with their head down and rubbed with a towel during $1 \mathrm{~min}$ to initiate spontaneous breathing (SB). If no SB or only some gasps were observed, the trachea was intubated and manual ventilation with room air was conducted for $1 \mathrm{~min}$. In piglets that did not respond with $\mathrm{SB}$ after $1 \mathrm{~min}$, manual ventilation was continued until an independent respiration was established (piglets with a heart beat were classified as nonsurviving (NSV) when no SB was attained at $15 \mathrm{~min}$ after birth).

As soon as respiration had been established in the surviving (SV) piglets, they were extubated, marked, weighed and placed into a tray which was heated by a heat pad covered with soft bedding, and by two $150-\mathrm{W}$ infrared lamps. At 5 and 10 min after birth the HR was measured and at 10, 30 and 60 min after birth blood samples from the UA were collected. Rectal tempera- 


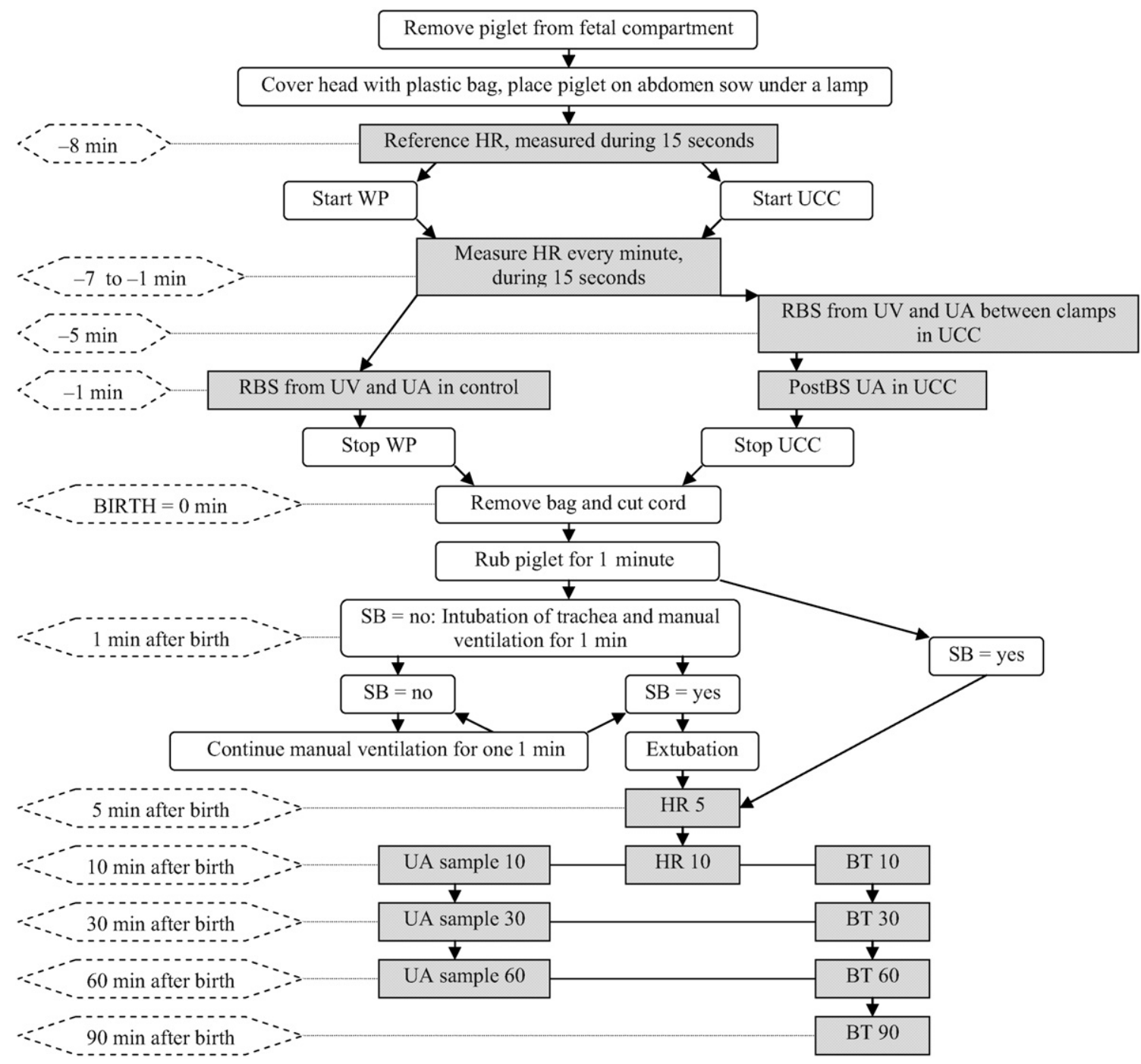

Fig. 1. Flow chart of the protocol applied after removal of each individual control and cord clamped piglet from its fetal compartment: HR, heart rate (beats/min); min, minute; WP, waiting period in control piglets (average duration: $7.0 \mathrm{~min}$ ); UCC, umbilical cord clamping in clamped piglets (average duration: $7.0 \mathrm{~min}$ ); RBS: reference blood sample, collected just prior to birth in control piglets $(-1 \mathrm{~min})$ or collected within 2 min after starting UCC from the double clamped area of the umbilical cord in clamped piglets ( $-5 \mathrm{~min}$ ); UV, umbilical vein; UA, umbilical artery; PostBS, postclamping blood sample, collected at birth of a clamped piglet; SB, spontaneous breathing; HR 5/10, heart rate measurement at 5/10 min after birth; UA sample 10/30/60, blood sample from the umbilical artery at 10/30/60 min after birth; BT 10/30/60/90, rectal temperature at 10/30/60/ $90 \mathrm{~min}$ after birth. The grey rectangles present samples that are collected/measurements that are performed. The hexagons indicate the different times with birth $=0 \mathrm{~min}$. The time schedule is based on the average duration of the WP and the UCC period. Consequently, when for example the UCC averaged $8 \mathrm{~min}$ in an individual piglet, the reference HR was measured at -9 min and the RBS from UV and UA were collected at -6 min.

tures (BT) were measured at 10, 30, 60 and 90 min after birth (see Fig. 1).

Each uterine incision was closed with one suture after the umbilical cord had been cut and subsequently that part of the uterus was carefully placed back into the abdominal cavity.

When the complete litter was removed from the uterus, the sow was euthanised with $\mathrm{T} 61^{\circledR}(200 \mathrm{mg}$ embutramide, $50 \mathrm{mg}$ mebezoniumjodide and $5 \mathrm{mg}$ tetracaïnehydrochloride per $\mathrm{mL}$; Intervet, Boxmeer, the Netherlands).

\subsection{Analysis of blood samples}

Blood samples from UV and UA were collected in heparinised syringes. The syringes with $0.5 \mathrm{~mL}$ blood were capped and placed on ice and samples were analysed within 10 min after collection with the iStat ${ }^{\mathbb{R}}$ 
Table 1

Mixed models for repeated measurements used for the analysis of blood values, heart rate and rectal temperature

\begin{tabular}{lllll}
\hline Variabele $^{\mathrm{a}}$ & \multicolumn{2}{l}{ Model } & & \\
\cline { 2 - 5 } & Blood values SV piglets & & \\
\hline$\mu^{\mathrm{c}}$ & Blood values NSV piglets & Heart rate SV piglets & Rectal temperature SV piglets \\
Fixed class variables & $X$ & $X$ & $X$ & $X$ \\
Time & $X$ & & & $X$ \\
Clamp & $X$ & $X$ & $X$ & $X$ \\
Time $\times$ clamp & $X$ & $X$ & $X$ & $X$ \\
Breath & $X$ & $X$ & $X$ & - \\
Fixed continuous variables & - & - & $X$ \\
Birth weight & $X$ & & $X$ & $X$ \\
CumST & $X$ & $X$ & $X$ & $X$ \\
Random class variable & $X$ & $X$ & $X$ & 36 \\
Sow & $X$ & $X$ & 36 &
\end{tabular}

$X$, variable included in the model.

a Time, time of blood sampling; clamp, whether the umbilical cord was clamped (1) or not $(0)$; time $\times$ clamp, interaction between the variables time and clamp; breath, spontaneous breathing (0) or manual ventilation with room air (1); birth weight, birth weight in g; CumST, cumulative sample time, i.e. time of collection of the reference blood samples from umbilical vein and umbilical artery, relative to removal of the first piglet in a litter from its fetal compartment.

b SV, surviving piglets; NSV, non-surviving piglets.

c $\mu$, fitted mean.

d Number of piglets included in the analyses.

Portable Clinical Analyser (i-Stat Europe, Birmingham, United Kingdom) for $\mathrm{pH}, p \mathrm{CO}_{2}(\mathrm{kPa}), \mathrm{HCO}_{3}{ }^{-}(\mathrm{mmol} /$ $\mathrm{L}), \mathrm{BE}_{\mathrm{ecf}}(\mathrm{mmol} / \mathrm{L})$ and lactate $(\mathrm{mmol} / \mathrm{L})$ values $\left(\mathrm{CG}^{+}\right.$ cartridges). Samples were analysed at a standard temperature of $37{ }^{\circ} \mathrm{C}$ and no corrections for body temperature were made. We have previously demonstrated that the iStat ${ }^{\circledR}$ is a reliable analyser for $\mathrm{pH}$, $p \mathrm{CO}_{2}, \mathrm{HCO}_{3}{ }^{-}$and $\mathrm{BE}_{\mathrm{ecf}}$ values in newborn piglets [15]. In cats and dogs the analysis of lactate values ranging from 0.4 to $15 \mathrm{mmol} / \mathrm{L}$ with the $\mathrm{iStat}^{\mathrm{R}}$ has been confirmed to be reliable $[20,21]$.

\subsection{Follow-up of the piglets}

When all SV piglets of a litter had been checked for their BT at 90 min after birth, they were transported to a pen provided with a bedding of wood shavings, an electrical heater and two 150-W infrared lamps. Fresh water and coffee milk $(690 \mathrm{~kJ}, 8.5 \mathrm{~g}$ protein, $13 \mathrm{~g}$ carbohydrates and $8.6 \mathrm{~g}$ fat per $100 \mathrm{~mL}$ ) (Goudband, Friesche Vlag, Nijkerk, the Netherlands) were available ad libitum in small feeding-troughs.

Upon their arrival in the pen, piglets received $20 \mathrm{~mL}$ warm colostrum, which had previously been collected from sows originating from the same farm and stored at $-20{ }^{\circ} \mathrm{C}$ until use. Subsequently, piglets were hand-fed four times a day with $20 \mathrm{~mL}$ coffee milk during the first
$48 \mathrm{~h}$ of age. As became obvious from continuous camera surveillance, all piglets were able to drink independently within $24 \mathrm{~h}$ of age.

Piglets were monitored daily for health status: rectal temperature, signs of diarrhoea, lameness and/or clinical signs indicating an infection of the respiratory tract, and body weight until the end of the experiment ( 24 or $72 \mathrm{~h}$ of age).

Control and clamped SV piglets were pair-wise selected (matched for body weight and gender) to be euthanised at $24 \mathrm{~h}(n=15)$ and $72 \mathrm{~h}(n=21)$ of age (i.e. 24 and $72 \mathrm{~h}$ after 'birth') with Euthasol ${ }^{\circledR} 40 \%$ intracardially (400 mg pentobarbital sodium $/ \mathrm{mL}$; A.S.T. Beheer BV, Oudewater, the Netherlands) for further analysis of tissue samples. This will be reported elsewhere.

\subsection{Statistical analysis}

All data have been analysed with SAS [22].

To evaluate whether $\mathrm{pH}, p \mathrm{CO}_{2}, \mathrm{HCO}_{3}{ }^{-}, \mathrm{BE}_{\mathrm{ecf}}$ and lactate values in RBS from UV and UA remained stable throughout the surgical procedure in SV and NSV piglets, a general linear model (GLM) was applied. In this model the continuous variable cumulative sample time (= cumST; i.e. time of collection of the RBS from $\mathrm{UV}$ and UA, relative to removal of the first piglet in a 
Table 2

Average acid-base balance values in reference blood samples from umbilical vein and umbilical artery in all (surviving $(n=36)$ and non-surviving $(n=11))$ piglets

\begin{tabular}{llllll}
\hline & $\mathrm{pH}$ & $p \mathrm{CO}_{2}(\mathrm{kPa})$ & $\mathrm{HCO}_{3}{ }^{-}(\mathrm{mmol} / \mathrm{L})$ & $\mathrm{BE}_{\mathrm{ecf}}(\mathrm{mmol} / \mathrm{L})$ & $\mathrm{Lactate}(\mathrm{mmol} / \mathrm{L})$ \\
\hline $\mathrm{UV}^{\mathrm{a}}$ & $7.38( \pm 0.04)$ & $7.0( \pm 0.7)$ & $31( \pm 2.7)$ & $6( \pm 3.0)$ & $3.3( \pm 0.9)$ \\
$\mathrm{UA}$ & $7.33( \pm 0.04)$ & $8.1( \pm 0.8)$ & $32( \pm 3.6)$ & $6( \pm 4.0)$ & $2.8( \pm 0.8)$ \\
\hline
\end{tabular}

Average values \pm S.D. are shown; number of observations ranges from 46 to 47 .

${ }^{\text {a }} \mathrm{UV}$, umbilical vein; UA, umbilical artery.

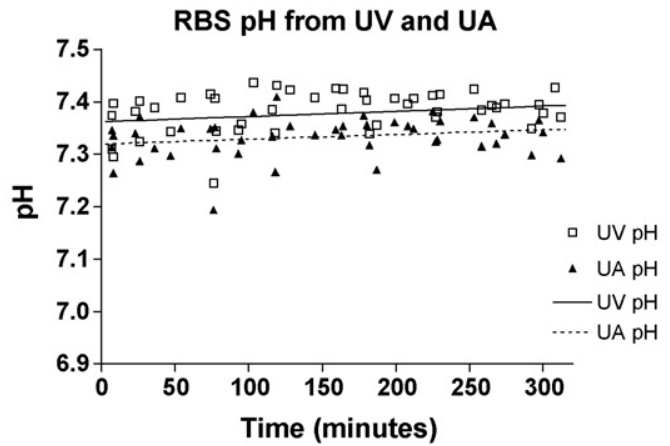

RBS $\mathrm{HCO}_{3}{ }^{-}$from UV and UA

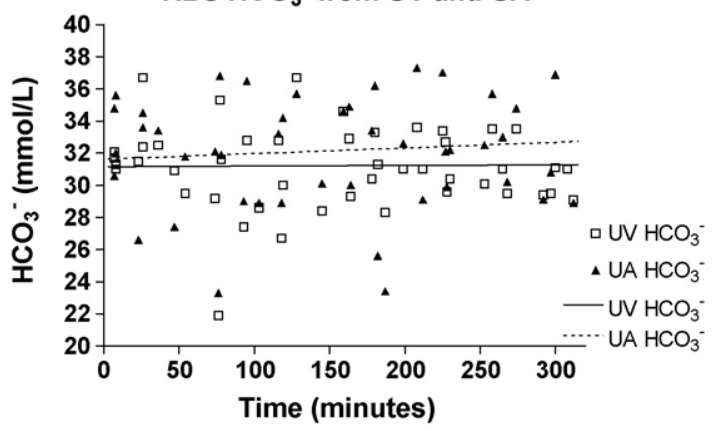

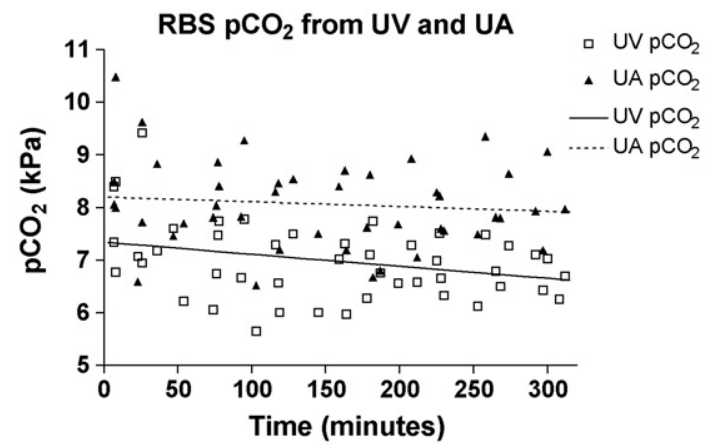

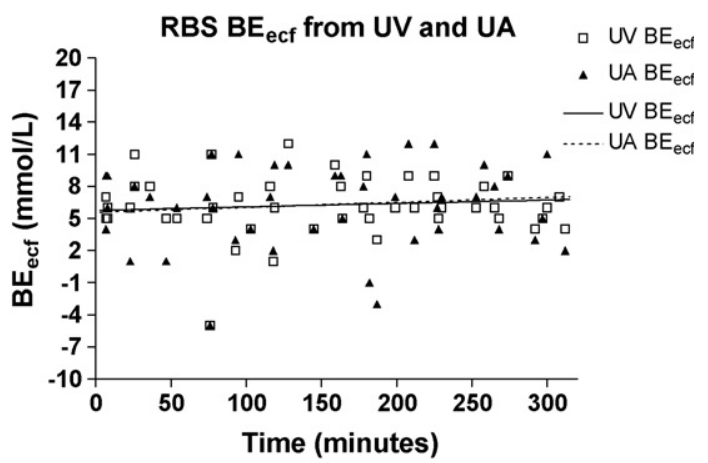

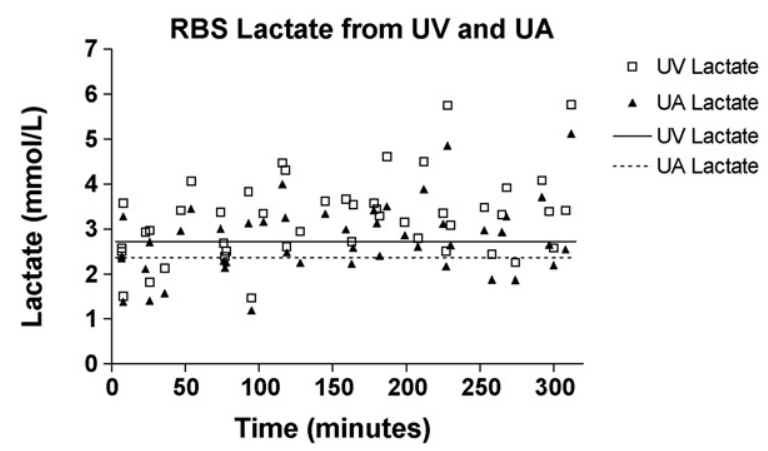

Fig. 2. Acid-base balance values in the reference blood samples from umbilical vein and umbilical artery in all (surviving and non-surviving) piglets, illustrating the fairly stable course of acid-base balance values throughout the surgical procedure: RBS, reference blood sample, collected just prior to birth in control piglets or collected within 2 min after starting umbilical cord clamping from the double clamped area of the umbilical cord in clamped piglets; UV, umbilical vein; UA, umbilical artery. 

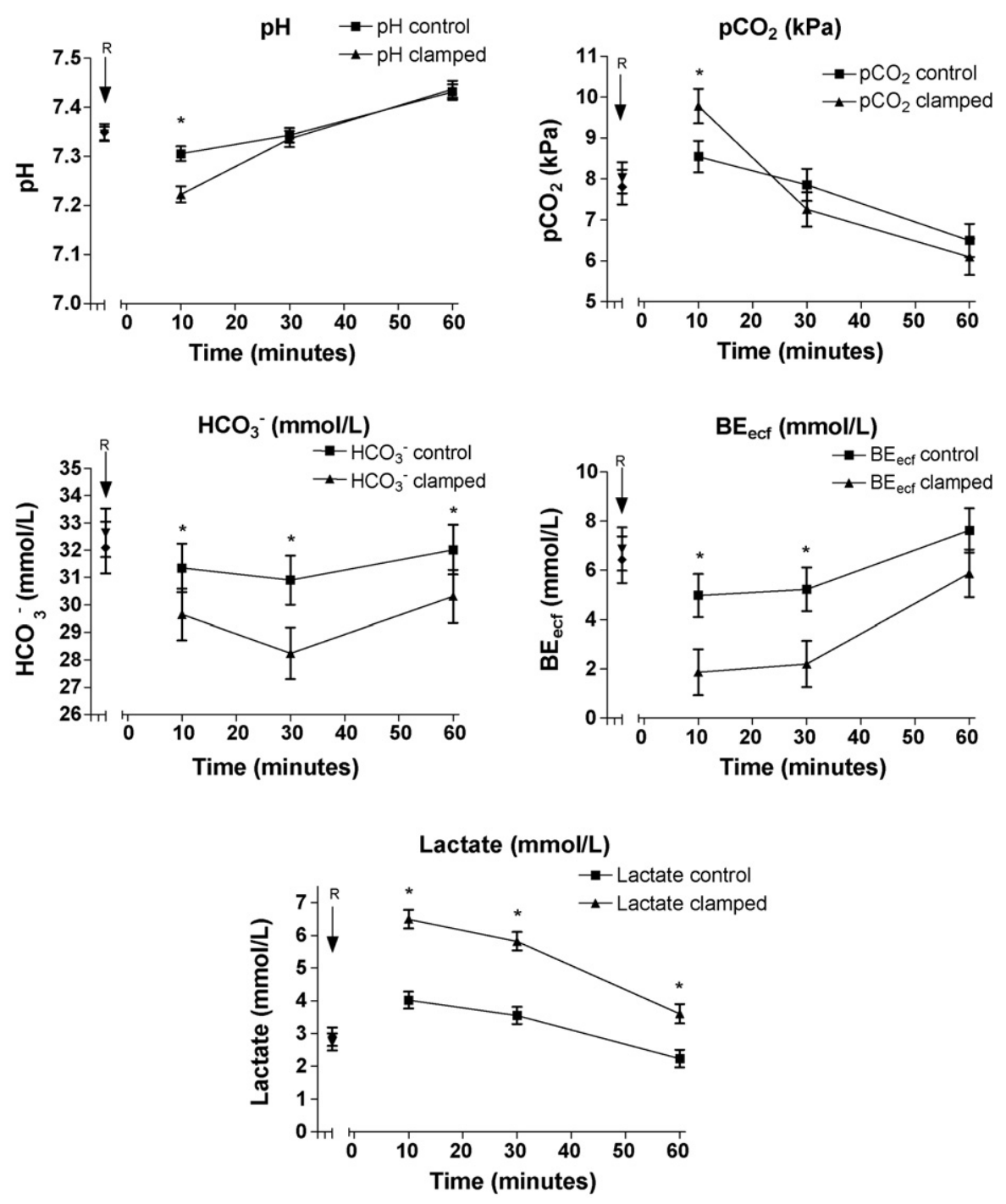

Fig. 3. LSmeans ( \pm S.E.M.) for $\mathrm{pH}, \mathrm{pCO}_{2}, \mathrm{HCO}_{3}{ }^{-}, \mathrm{BE}_{\mathrm{ecf}}$ and lactate in umbilical artery samples of surviving control piglets and piglets subjected to umbilical cord clamping, illustrating the shift towards a more pronounced mixed respiratory-metabolic acidosis in surviving clamped piglets, as compared to surviving control piglets: $\left(^{*}\right)$ indicates significant differences between control and clamped piglets $(P$-value $<0.05)$ at a given time point. $\mathrm{HCO}_{3}{ }^{-}$values tended to be significantly affected by the time $\times$clamp interaction. $\mathrm{R}=\mathrm{RBS}=$ reference blood sample, collected just prior to birth in control piglets or collected within 2 min after starting umbilical cord clamping from the double clamped area of the umbilical cord in clamped piglets; time 10, 30 and 60 min indicate the time of sampling after birth; control, control piglets; clamped, piglets that were subjected to umbilical cord clamping during caesarean section.

litter from its fetal compartment) and the class variable sow were included. The reference HR (in SV and NSV piglets) and the BT measured at 10 min after birth (in SV piglets) were analysed in a similar way to check for stability of these values throughout the procedure.

The mixed procedure was applied to analyse the effect of UCC in SV piglets on the repeated measurements of umbilical artery $\mathrm{pH}, p \mathrm{CO}_{2}, \mathrm{HCO}_{3}{ }^{-}, \mathrm{BE}_{\text {ecf }}$ and lactate in the RBS from the UA and the blood samples collected from the UA at 10, 30 and $60 \mathrm{~min}$ after birth. The following fixed variables were included in the model: time (time of blood sampling), clamp (umbilical cord clamping yes/no), time $\times$ clamp (interaction between the variables time and clamp), breath (spontaneous respiration or manual ventilation after birth) (all class variables) and the continuous variables birth weight (in g) and cumST. As preliminary analysis showed that duration of the WP or the UCC did not affect acid-base balance values, this variable was omitted from the model. The blood values were set as repeated measurements by 'time', the covariance structure was defined as compound symmetry and individual piglets were identified as 
Table 3

LSmeans of the acid-base balance values in umbilical artery blood of surviving control and clamped piglets for each time point

\begin{tabular}{|c|c|c|c|c|}
\hline & Time $^{a}$ & Control & Clamped & $P$-value ${ }^{*}$ \\
\hline $\mathrm{pH}$ & $\begin{array}{l}\text { RBS } \\
10 \\
30 \\
60\end{array}$ & $\begin{array}{l}7.35^{\mathrm{a}} \\
7.31^{\mathrm{ab}} \\
7.34^{\mathrm{b}} \\
7.43^{\mathrm{ab}}\end{array}$ & $\begin{array}{l}7.35^{\mathrm{a}} \\
7.22^{\mathrm{ab}} \\
7.34^{\mathrm{b}} \\
7.44^{\mathrm{ab}}\end{array}$ & $\begin{array}{l}\text { n.s. } \\
<0.0001 \\
\text { n.s. } \\
\text { n.s. }\end{array}$ \\
\hline$p \mathrm{CO}_{2}(\mathrm{kPa})$ & $\begin{array}{l}\text { RBS } \\
10 \\
30 \\
60\end{array}$ & $\begin{array}{l}8.0^{\mathrm{a}} \\
8.5^{\mathrm{b}} \\
7.9^{\mathrm{c}} \\
6.5^{\mathrm{abc}}\end{array}$ & $\begin{array}{l}7.8^{\mathrm{a}} \\
9.8^{\mathrm{ab}} \\
7.3^{\mathrm{bc}} \\
6.1^{\mathrm{ac}}\end{array}$ & $\begin{array}{l}\text { n.s. } \\
0.0038 \\
\text { n.s. } \\
\text { n.s. }\end{array}$ \\
\hline $\mathrm{HCO}_{3}{ }^{-}(\mathrm{mmol} / \mathrm{L})$ & $\begin{array}{l}\text { RBS } \\
10 \\
30 \\
60\end{array}$ & $\begin{array}{l}33^{\mathrm{ab}} \\
31^{\mathrm{a}} \\
31^{\mathrm{bc}} \\
32^{\mathrm{c}}\end{array}$ & $\begin{array}{l}32^{\mathrm{ab}} \\
30^{\mathrm{a}} \\
28^{\mathrm{ac}} \\
30^{\mathrm{bc}}\end{array}$ & $\begin{array}{l}\text { n.s. } \\
0.0175 \\
0.0003 \\
0.0257\end{array}$ \\
\hline $\mathrm{BE}_{\mathrm{ecf}}(\mathrm{mmol} / \mathrm{L})$ & $\begin{array}{l}\text { RBS } \\
10 \\
30 \\
60\end{array}$ & $\begin{array}{l}7^{\mathrm{ab}} \\
5^{\mathrm{ac}} \\
5^{\mathrm{bd}} \\
8^{\mathrm{cd}}\end{array}$ & $\begin{array}{l}6^{\mathrm{ab}} \\
2^{\mathrm{ac}} \\
2^{\mathrm{bd}} \\
6^{\mathrm{cd}}\end{array}$ & $\begin{array}{l}\text { n.s. } \\
0.0003 \\
0.0005 \\
0.0531\end{array}$ \\
\hline Lactate $(\mathrm{mmol} / \mathrm{L})$ & $\begin{array}{l}\text { RBS } \\
10 \\
30 \\
60\end{array}$ & $\begin{array}{l}2.7^{\mathrm{a}} \\
4.0^{\mathrm{a}} \\
3.6^{\mathrm{a}} \\
2.2^{\mathrm{a}}\end{array}$ & $\begin{array}{l}2.9^{\mathrm{a}} \\
6.5^{\mathrm{a}} \\
5.8^{\mathrm{a}} \\
3.6^{\mathrm{a}}\end{array}$ & $\begin{array}{l}\text { n.s. } \\
<0.0001 \\
<0.0001 \\
<0.0001\end{array}$ \\
\hline
\end{tabular}

LSmeans in the same column with the same superscript(s), differ significantly (within the same blood parameter); LSmeans without any corresponding superscripts do not differ significantly.

a Time, time of blood sampling in minutes after birth; RBS: reference blood sample, collected just prior to birth in control piglets or collected within 2 min after starting umbilical cord clamping from the double clamped area of the umbilical cord in clamped piglets; control, surviving control piglets; clamped, surviving piglets that were subjected to umbilical cord clamping during caesarean section.

* $P$-values $<0.05$ indicate significant differences between blood values of control and clamped piglets at a given time point; $0.05<P$ value $<0.1$ indicates a tendency for blood values to differ between control and clamped piglets at a given time point.

subject. Sow was included as random class variable (see Table 1). For NSV piglets, an identical mixed model was applied to evaluate the effect of UCC on $\mathrm{pH}, p \mathrm{CO}_{2}$, $\mathrm{HCO}_{3}{ }^{-}, \mathrm{BE}_{\text {ecf }}$ and lactate values in the RBS from the UA and the blood samples collected from the UA at $10 \mathrm{~min}$ after birth. The variable breath was removed from the model as all NSV piglets were subjected to manual ventilation after birth (see Table 1).

To evaluate the effect of UCC on the course of the HR in SV piglets during the WP and the UCC period and at 5 and 10 min after birth, the same mixed model (with exclusion of the variable breath) was used (see Table 1). Due to the limited amount of data, this analysis was not conducted in NSV piglets. The effect of UCC on BT at 10, 30, 60 and 90 min after birth in SV piglets was analysed in a similar way (see Table 1).
Daily changes in body weight (in g/day) at $24 \mathrm{~h}$ (piglet weight at $24 \mathrm{~h}-$ birth weight) $\left(\Delta \mathrm{BW}_{24}\right), 48 \mathrm{~h}$ ((piglet weight at $48 \mathrm{~h}-$ birth weight $) / 2)\left(\Delta \mathrm{BW}_{48}\right)$ and $72 \mathrm{~h}$ ((piglet weight at $72 \mathrm{~h}-$ birth weight $) / 3)\left(\Delta \mathrm{BW}_{72}\right)$ $\mathrm{h}$ of age were analysed with a mixed model (without repeated measurements) including the fixed variables clamp and breath and the continuous variable birth weight (in $\mathrm{g}$ ). Corrections for the class variable sow were included as random effect.

$P$-values equal to or less than 0.05 were considered to be significant. When a class variable was significant, multiple comparisons were performed with adjustments according to Tukey-Kramer (pdiff in the mixed procedure of the SAS system).

\section{Results}

\subsection{General results}

It took on average 291 (S.D. \pm 44 ) min to remove all piglets from the uterus, with a mean interval of 29 (S.D. \pm 7 ) min between individual piglets.

Average ( \pm S.D.) acid-base balance values of reference blood samples (RBS) from the umbilical vein (UV) and umbilical artery (UA) of surviving (SV) and non-surviving (NSV) piglets are shown in Table 2. $\mathrm{HCO}_{3}{ }^{-}$and $\mathrm{BE}_{\text {ecf }}$ values of RBS from the UV were not significantly affected by cumulative sample time (cumST) (Fig. 2). An increasing cumST resulted in a very small but significant increase in $\mathrm{pH}$ and lactate and a small but significant decrease in $p \mathrm{CO}_{2}$ values in RBS from the UV. Lactate values in RBS from the UA (see Fig. 2) increased significantly with an increasing cumST, whereas $\mathrm{pH}, p \mathrm{CO}_{2}, \mathrm{HCO}_{3}{ }^{-}$and $\mathrm{BE}_{\text {ecf }}$ values in RBS from the UA remained constant throughout the surgical procedure. In RBS from both UV and UA, there was a significant effect of the sow on all acid-base balance values.

Reference heart rate (HR) in SV and NSV piglets and rectal temperature (BT) at 10 min of life in SV piglets were also significantly affected by sow but not by cumST (data not shown).

All piglets $(n=47)$, except one, derived by caesarean section were alive upon exteriorisation. Umbilical cords were clamped in 23 piglets during on average 7.0 (S.D. \pm 1.1 ; range 5.0-8.0) $\mathrm{min}$ and the waiting period (WP) (24 piglets) lasted on average 7.0 (S.D. \pm 1.9 ; range 5.0-9.0) min. In total, 21 control and 21 clamped piglets were supported in establishing respiration by manual ventilation with room air. In four control (average birth weight 1423 (S.D. \pm 528) g; WP 6.8 (S.D. \pm 1.0$) \mathrm{min}$ ) and seven clamped piglets (average 

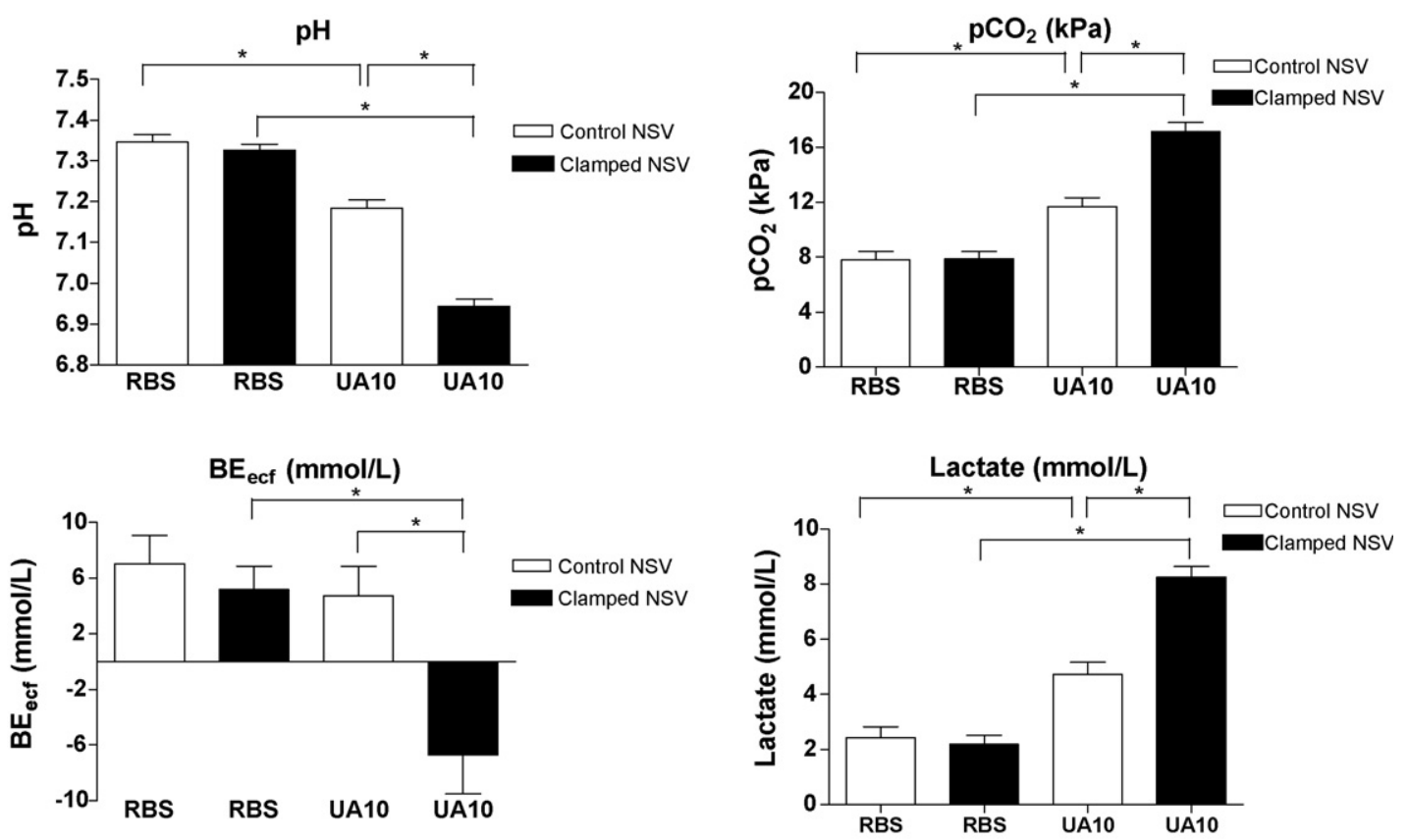

Fig. 4. LSmeans ( \pm S.E.M.) for $\mathrm{pH}, p \mathrm{CO}_{2}, \mathrm{BE}_{\mathrm{ecf}}$ and lactate in umbilical artery samples of non-surviving control piglets and non-surviving piglets subjected to umbilical cord clamping, illustrating the shift towards a more pronounced mixed respiratory-metabolic acidosis in non-surviving clamped piglets, as compared to non-surviving control piglets: $\left(^{*}\right)$ indicates that acid-base balance values differ significantly $(P$-value $<0.05)$. $\mathrm{HCO}_{3}{ }^{-}$values were not affected by the time $\times$clamp interaction and are therefore not shown. RBS: reference blood sample, collected just prior to birth in control piglets or collected within 2 min after starting umbilical cord clamping from the double clamped area of the umbilical cord in clamped piglets; UA10, blood sample collected from the umbilical artery at $10 \mathrm{~min}$ after birth; control, control piglets; clamped, piglets that were subjected to umbilical cord clamping during caesarean section. Number of observations: four piglets in the control and seven piglets in the clamped groups.

birth weight 1259 (S.D. \pm 375) g; average duration of umbilical cord clamping (UCC) 7.7 (S.D. \pm 0.5 ) min) no spontaneous breathing (SB) was established at $15 \mathrm{~min}$ after birth and these piglets were classified as NSV. Duration of the WP and the UCC did not differ significantly between SV and NSV piglets.

Average birth weight of SV control piglets (1336 (S.D. \pm 417$) \mathrm{g}$ ) and of SV clamped piglets (1392 (S.D. \pm 403$) \mathrm{g}$ ) did not differ significantly from birth weights of NSV piglets. In the follow-up period (which started when the piglets were placed into the pen) no mortality was observed.

\subsection{Effects of umbilical cord clamping}

Clamping of the umbilical cord in SV piglets resulted in significantly lower $\mathrm{pH}$ and $\mathrm{BE}_{\mathrm{ecf}}$ and significantly higher $p \mathrm{CO}_{2}$ and lactate values in umbilical artery blood at $10 \mathrm{~min}$ after birth (compared to control piglets), independently of spontaneous breathing or manual ventilation, birth weight and cumST (see Fig. 3; the accompanying LSmeans for the time $\times$ clamp interaction are shown in Table 3 ).
Differences in $\mathrm{BE}_{\text {ecf }}$ values between clamped and control piglets remained significant until $30 \mathrm{~min}$ after birth; for lactate values this difference was present until at least $60 \mathrm{~min}$ after birth (Fig. 3 and Table 3).

In the NSV piglets, UCC resulted in significantly lower $\mathrm{pH}$ and $\mathrm{BE}_{\text {ecf }}$ values and significantly higher $p \mathrm{CO}_{2}$ and lactate values at $10 \mathrm{~min}$ after birth, independently of birth weight and cumST (Fig. 4); $\mathrm{HCO}_{3}{ }^{-}$values at $10 \mathrm{~min}$ in NSV piglets were not affected by UCC.

In SV clamped piglets the average reference HR was significantly higher than the average HR during the UCC period (see Fig. 5). During the UCC period, clamping resulted in significantly lower HR as compared to the control piglets in the WP (Fig. 5). Furthermore, whereas the control piglets showed a rather stable HR during the WP, in the clamped piglets a significant bradycardia around 6-3 min before birth was demonstrated. At 5 and 10 min after birth, no significant difference between HR of control and clamped piglets was present anymore although in both groups significantly lower HR were measured as compared to the reference HR (see Fig. 5). 


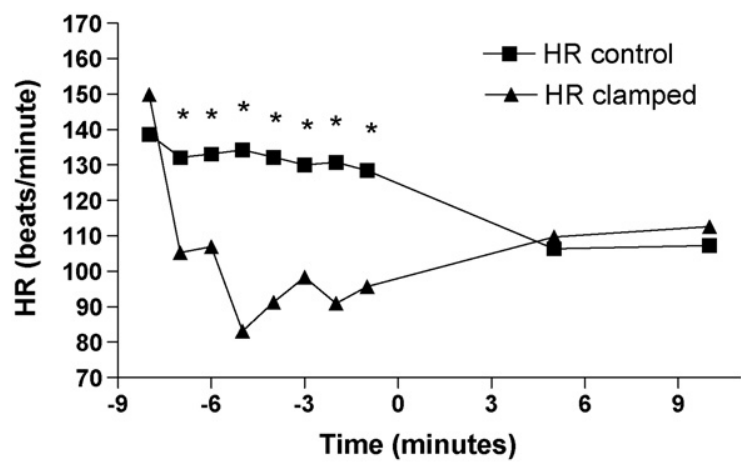

Fig. 5. LSmeans ( \pm S.E.M.) of the HR of surviving control piglets and piglets that were subjected to umbilical cord clamping, clearly illustrating the significant lower HR in surviving clamped piglets during umbilical cord clamping as compared to the surviving control piglets during the waiting period: $(*)$ indicates significant differences between control and clamped piglets at a given time point $(P$ value $<0.05$ ). HR, heart rate (beats/min); control, control piglets; clamped, piglets that were subjected to umbilical cord clamping during caesarean section. Reference measurements were performed at $-8 \mathrm{~min}$; cord clamping or waiting period from -7 to $0 \mathrm{~min}$ and birth at 0 min (both the WP and the UCC period were finished by removing the bag and simultaneous cutting of the umbilical cord, defined as 'birth' of the piglet). Number of observations per time ranges from 12 to 34 .

No significant effect of UCC on BT at 10, 30, 60 and 90 min after birth was observed in SV piglets. However, BT in both control and clamped piglets at $60\left(35.8{ }^{\circ} \mathrm{C}\right)$ and $90\left(36.9^{\circ} \mathrm{C}\right)$ min after birth were significantly higher than at $10\left(34.2^{\circ} \mathrm{C}\right)$ and $30\left(34.1^{\circ} \mathrm{C}\right)$ min after birth. Besides, BT at 90 min after birth was significantly higher than at $60 \mathrm{~min}$.

Daily changes in body weight ( $\Delta \mathrm{BW}$ in g/day) at 24 , 48 and $72 \mathrm{~h}$ of life were not significantly affected by UCC. Both control and clamped piglets lost weight during the first $48 \mathrm{~h}$ of life; in control piglets $\Delta \mathrm{BW}_{24}$ averaged -146 (S.E. 32) g/day and $\Delta \mathrm{BW}_{48}$ averaged -50 (S.E. 13.4) g/day. In clamped piglets a mean $\Delta \mathrm{BW}_{24}$ of -187 (S.E. 35) g/day and a mean $\Delta \mathrm{BW}_{48}$ of -40 (S.E. 16) $\mathrm{g} /$ day were observed. $\Delta \mathrm{BW}_{72}$ was 0.5 (S.E. 17) g/day in control and 4 (S.E. 20) g/day in clamped piglets.

Irrespective of cord clamping, the 31 piglets that had needed assistance for the establishment of respiration, showed significantly less body weight loss at $24 \mathrm{~h}$ after birth (-82 (S.E. 27) g/day versus -251 (S.E. 48) g/day in five spontaneous breathing piglets). The remaining 18 , manually ventilated piglets also showed significantly less body weight loss at $48 \mathrm{~h}$ after birth $(-0.4$ (S.E. 9) g/day versus -90 (S.E. 22) g/day in the remaining three spontaneous breathing piglets) and a significantly higher increase in body weight (36 (S.E.
12) $g /$ day) as compared to spontaneously breathing piglets ( -32 (S.E. 27) g/day) at $72 \mathrm{~h}$ of age. Increased birth weights resulted in a significant increase of $\Delta \mathrm{BW}_{48}$ and $\Delta \mathrm{BW}_{72}$.

\section{Discussion}

As several studies have reported on the importance of the integrity of the umbilical cord in the development of birth asphyxia [1,16], we developed a model of umbilical cord clamping (UCC) in late pregnant sows to mimic the evolvement of birth asphyxia in natural farrowings. A main prerequisite for this envisaged model of UCC is the stability of acid-base balance values in reference blood samples (RBS) from umbilical vein (UV) and umbilical artery (UA) throughout the surgical procedure, as the total duration of the surgical procedure per sow averaged almost $5 \mathrm{~h}(291 \pm 44 \mathrm{~min})$. Stability of acid-base balance values should guarantee well comparable reference values for both control and clamped piglets within and between litters. In the RBS from the UV, a gradual, small increase of $\mathrm{pH}$ and lactate values and a decrease of $p \mathrm{CO}_{2}$ values were observed (Fig. 2). Yet, the average acid-base balance values in RBS from the UA remained fairly stable throughout the surgical procedure (Table 2) and are well in range with values reported in newborn piglets in literature [3,15,23-26]. Only a gradual, small increase of lactate values in RBS from the UA was observed. Additionally, reference heart rates (HR) in surviving (SV) and nonsurviving (NSV) piglets and rectal temperatures (BT) at $10 \mathrm{~min}$ after birth in SV piglets were not affected by cumST. These data indicate that a stable starting position of both control and clamped piglets existed, despite differences in the moment of exteriorization from the uterus.

In contrast to intra-partum hypoxia experienced during vaginal delivery (i.e. a non-standardised model of birth asphyxia) as described by Trujillo-Ortega et al. [2], it should be realised that in our model, all piglets were subjected to a certain degree of general anaesthesia with isoflurane. This is illustrated by the finding that in total 42 piglets $(89 \%)$ had to be assisted in the establishment of independent respiration. Moon et al. [27] concluded that isoflurane generally is a safe anaesthetic for induction and maintenance of general anaesthesia during caesarean sections in different dog breeds. In the study presented here, 1.6-1.8\% isoflurane was applied for maintenance of anaesthesia. Vaillancourt et al. [28] demonstrated that isoflurane applied at $2.5 \%$ (with $\mathrm{N}_{2} \mathrm{O}$ ) during 8 min, hardly compromised respiration and apparently resulted in good systemic 
and brain oxygenation in term neonatal rat puppies. However, piglets in our study were subjected to isoflurane anaesthesia for a period ranging from 52 to 366 min.

It might be argued to what extent the administration of ketamine, an antagonist of $\mathrm{N}$-methyl-D-aspartate (NMDA) receptors [29], affects the adverse changes observed in the pathogenesis of delayed brain damage resulting from hypoxia-ischemia. These adverse changes include, among others, an increased agonistic activity towards brain NMDA receptors, resulting from accumulated glutamate in synaptic clefts [4]. Consequently, considering the relative short-during anaesthesia resulting from ketamine [29], possibly distorting effects of ketamine, given to the sow, on NMDA receptors of her piglets were minimised by removing the first piglet from its fetal compartment at $45 \mathrm{~min}$ after the last ketamine administration to the sow.

In the SV control piglets a mild mixed respiratorymetabolic acidosis at $10 \mathrm{~min}$ after birth was observed (see Fig. 3 and Table 3). Similar findings were reported by Wilhelm et al. [26] who demonstrated a further drop in $\mathrm{pH}, \mathrm{HCO}_{3}{ }^{-}$and $\mathrm{BE}_{\text {ecf }}$ values at $10 \mathrm{~min}$ after birth under normal farm conditions. $p \mathrm{CO}_{2}$ values in $\mathrm{SV}$ control piglets showed no significant dip what is also in line with the findings of Wilhelm et al. [26]. A significantly more pronounced mixed respiratorymetabolic acidosis developed in the SV clamped piglets. Herpin et al. [3] measured average plasma $\mathrm{pH}$ values of 7.00 and $p \mathrm{CO}_{2}$ values of more than $9 \mathrm{kPa}$ in mixed cord blood at birth in highly asphyxiated liveborn piglets under normal farm conditions, and this is well below the average $\mathrm{pH}$ of 7.22 found at $10 \mathrm{~min}$ of life in our SV clamped piglets. However, average $p \mathrm{CO}_{2}$ values in our clamped piglets at $10 \mathrm{~min}$ of life were well in range with the $p \mathrm{CO}_{2}$ values in highly asphyxiated piglets as reported by Herpin et al. [3].

In contrast to $\mathrm{pH}$ and $p \mathrm{CO}_{2}$ values, $\mathrm{BE}_{\mathrm{ecf}}$ and lactate values in umbilical artery blood from SV clamped piglets remained significantly affected by UCC until 30 and $60 \mathrm{~min}$ after birth, respectively, emphasising a more long-term effect of UCC on metabolic parameters of the acid-base balance. Despite the significant decrease, plasma $\mathrm{BE}_{\text {ecf }}$ values in $\mathrm{SV}$ clamped piglets remained positive, whereas negative $\mathrm{BE}_{\text {ecf }}$ values are considered to be a common finding in asphyxiated newborns [30]. In addition, compared to average plasma lactate values of $7.2-9.6 \mathrm{mmol} / \mathrm{L}$ reported in highly asphyxiated liveborn piglets $[2,3]$, the average lactate value of $6.5 \mathrm{mmol} / \mathrm{L}$ observed at $10 \mathrm{~min}$ of life in the SV clamped piglets in this study is slightly lower. In our model of UCC, the additional effects of successive uterine contractions that are present during the expulsive stage of farrowing [31] are lacking, as the sows were not yet in partu during the surgical procedure. This latter finding was confirmed by the high plasma progesterone concentrations in blood samples collected from each sow at the day of the caesarean section (data not shown). Uterine contractions result in decreased uteroplacental blood flow [32] and thereby a reduced oxygen supply to the fetus. This might indicate that, although both an increasing rank (relative position in the birth order) and an increased cumulative birth interval result in a more pronounced mixed respiratory-metabolic acidosis in liveborn piglets [15], the occurrence of cumulative uterine contractions creates a certain threshold in the acid-base balance values below which an additional effect of traction, occlusion or rupture of the umbilical cord is decisive in the evolvement of severe birth asphyxia. This might also explain the relative mild mixed respiratory-metabolic acidosis resulting from UCC in the model presented here. The importance of the process of farrowing as a general risk factor for the occurrence of perinatal mortality is further emphasized by the fact that only one piglet ( $2 \%$ of the total number of piglets in this study) was already dead upon exteriorization. Similar findings were reported by Friendship et al. [33] who conducted elective caesarean sections in late pregnant sows and concluded that dead, full-grown piglets were absent in utero in $87 \%$ of the litters.

Remarkably, four control piglets did not succeed in establishing independent respiration and no clear explanation is available for this finding. Leenhouwers et al. [34] provided evidence for the presence of a genetic background for farrowing survival, independent from the duration of farrowing, and this might have attributed to the inexplicable resuscitation failure in these NSV control piglets.

Apparently, a considerable variation in individual susceptibility for birth asphyxia exists, as both the duration of UCC and birth weights did no differ significantly between NSV and SV clamped piglets. A similar variation in individual ability to withstand birth asphyxia is mentioned by Randall [19]. The NSV clamped piglets $(n=7)$ were indeed highly asphyxiated as indicated by their average $\mathrm{pH}$ (6.94), $p \mathrm{CO}_{2}$ $(17.16 \mathrm{kPa}), \quad \mathrm{BE}_{\mathrm{ecf}} \quad(-7 \mathrm{mmol} / \mathrm{L})$ and lactate $(8.3 \mathrm{mmol} / \mathrm{L})$ values at $10 \mathrm{~min}$ after birth, while their RBS were normal (see Fig. 4).

The HR values observed before the UCC or waiting period (WP) started were in range with values mentioned by Taverne and Randall [35]. UCC resulted in significantly lower HR compared to control piglets 
and a significant initial dip in the course of the HR was observed in clamped piglets at 6-3 min before birth, followed by a gradual increase of the HR (see Fig. 5). This latter finding is well in line with the findings of Randall [19].

Herpin et al. [13] concluded that severe perinatal asphyxia resulted in only minor alterations of thermoregulation capacities in newborn piglets. Therefore, the absence of an effect of UCC on BT in the study presented here might well be explained by the mild degree of perinatal asphyxia achieved in this UCC model. The dip in the BT at $30 \mathrm{~min}$ of life in both control and clamped piglets is a common finding in newborn piglets [36].

The mild degree of perinatal asphyxia achieved in our UCC model also failed to affect daily changes in body weight $(\triangle \mathrm{BW})$. The rather short period of followup (maximal 3 days) might be a crucial factor, especially when comparing this with the 10 day follow-up in control and asphyxiated piglets as mentioned by Herpin et al. [3]. Next to that, piglets were not fostered by a sow and although camera surveillance showed that all piglets were able to drink independently within $24 \mathrm{~h}$ of life, negative effects of the artificial fostering on $\Delta \mathrm{BW}$ can not be excluded. Indeed, all piglets in our study lost at least some body weight during the first $24 \mathrm{~h}$ of age. This might be attributed to suboptimal feeding as under regal farm conditions only some piglets, born from normal, uncomplicated farrowings, loose body weight during the first $24 \mathrm{~h}$ of life. In some cases, piglets have not yet been able to compensate for these losses at $72 \mathrm{~h}$ of life (personal communication).

Remarkably, manually ventilated piglets showed significantly lower weight losses at $24(n=31) \mathrm{h}$ and 48 $(n=18) \mathrm{h}$ of life than the limited number of spontaneous breathing piglets $(n=5$ at $24 \mathrm{~h}$ and $n=3$ at $48 \mathrm{~h}$ of life, respectively), irrespective of cord clamping. However, no clear explanation is currently available for the effect of manual ventilation on subsequent changes in body weight and this issue needs to be further investigated.

In conclusion, the mixed respiratory-metabolic acidosis that arises in the SV clamped piglets after a 7 min during UCC is not as severe as other investigators have found in highly asphyxiated newborn piglets and the repeatability of the model is compromised by the considerable variation in the individual response to UCC.

Nevertheless, this model resulted in a renewed insight into the relative importance of the umbilical cord in the evolvement of birth asphyxia, indicating that the combined effects of successive uterine contractions and traction, occlusion or rupture of the umbilical cord during vaginal delivery, together determine the degree of perinatal asphyxia.

\section{Acknowledgements}

The authors would like to thank Susanne Döll, Lilia Goyenechea Jaramillo, Nanne Hendricks, Riek van Oord, Felice Woutersen and Elly Zeinstra for their support during the practical part of the study presented here. The authors would also like to thank Johanna Fink-Gremmels for critically reading the manuscript.

\section{References}

[1] Randall GC. The relationship of arterial blood $\mathrm{pH}$ and $p \mathrm{CO}_{2}$ to the viability of the newborn piglet. Can J Comp Med 1971;35:141-6.

[2] Trujillo-Ortega ME, Mota-Rojas D, Olmos-Hernandez A, Alonso-Spilsbury M, Gonzalez M, Orozco H, et al. A study of piglets born by spontaneous parturition under uncontrolled conditions: could this be a naturalistic model for the study of intrapartum asphyxia? Acta Biomed 2007;78:29-35.

[3] Herpin P, Le Dividich J, Hulin JC, Fillaut M, De Marco F, Bertin $R$. Effects of the level of asphyxia during delivery on viability at birth and early postnatal vitality of newborn pigs. J Anim Sci 1996;74:2067-75.

[4] Shalak L, Perlman JM. Hypoxic-ischemic brain injury in the term infant-current concepts. Early Hum Dev 2004;80:125-41.

[5] David JC, Boelens WC, Grongnet JF. Up-regulation of heat shock protein HSP 20 in the hippocampus as an early response to hypoxia of the newborn. J Neurochem 2006;99:570-81.

[6] Louapre P, Grongnet JF, Tanguay RM, David JC. Effects of hypoxia on stress proteins in the piglet heart at birth. Cell Stress Chaperones 2005;10:17-23.

[7] Nefti O, Grongnet JF, David JC. Overexpression of alphaB crystallin in the gastrointestinal tract of the newborn piglet after hypoxia. Shock 2005;24:455-61.

[8] Vannucci RC, Perlman JM. Interventions for perinatal hypoxicischemic encephalopathy. Pediatrics 1997;100:1004-14.

[9] Roohey T, Raju TN, Moustogiannis AN. Animal models for the study of perinatal hypoxic-ischemic encephalopathy: a critical analysis. Early Hum Dev 1997;47:115-46.

[10] Thoresen M, Haaland K, Loberg EM, Whitelaw A, Apricena F, Hanko E, et al. A piglet survival model of posthypoxic encephalopathy. Pediatr Res 1996;40:738-48.

[11] Ioroi T, Peeters-Scholte C, Post I, Leusink C, Groenendaal F, van Bel F. Changes in cerebral haemodynamics, regional oxygen saturation and amplitude-integrated continuous EEG during hypoxia-ischaemia and reperfusion in newborn piglets. Exp Brain Res 2002;144:172-7.

[12] Peeters-Scholte C, Braun K, Koster J, Kops N, Blomgren K, Buonocore G, et al. Effects of allopurinol and deferoxamine on reperfusion injury of the brain in newborn piglets after neonatal hypoxia-ischemia. Pediatr Res 2003;54:516-22.

[13] Herpin P, Wosiak F, Le Dividich J, Bertin R. Effects of acute asphyxia at birth on subsequent heat production capacity in newborn pigs. Res Vet Sci 1999;66:45-9. 
[14] van Dijk AJ, Jonker FH, Taverne MA. The effect of administration of 2-iminobiotin at birth on growth rates, morbidity and mortality in piglets under farm conditions. Livest Sci 2008;115:129-36.

[15] van Dijk AJ, van der Lende T, Taverne MA. Acid-base balance of umbilical artery blood of liveborn piglets at birth and its relation with factors affecting delivery of individual piglets. Theriogenology 2006;66:1824-33.

[16] Christianson WT. Stillbirths, mummies, abortions, and early embryonic death. Vet Clin North Am Food Anim Pract 1992;8:623-39.

[17] Randall GC. Observations on parturition in the sow. II. Factors influencing stillbirth and perinatal mortality. Vet Rec 1972;90: $183-6$.

[18] Mota-Rojas D, Martinez-Burnes J, Trujillo-Ortega ME, AlonsoSpilsbury ML, Ramirez-Necoechea R, Lopez A. Effect of oxytocin treatment in sows on umbilical cord morphology, meconium staining, and neonatal mortality of piglets. Am J Vet Res 2002;63:1571-4.

[19] Randall GC. Studies on the effect of acute asphyxia on the fetal pig in utero. Biol Neonate 1979;36:63-9.

[20] Acierno MJ, Mitchell MA. Evaluation of four point-of-care meters for rapid determination of blood lactate concentrations in dogs. J Am Vet Med Assoc 2007;230:1315-8.

[21] Acierno MJ, Johnson ME, Eddleman LA, Mitchell MA. Measuring statistical agreement between four point of care (POC) lactate meters and a laboratory blood analyzer in cats. J Feline Med Surg 2007;[Epub ahead of print].

[22] SAS/STAT. User's guide. Cary, NC: SAS Institute; 1990.

[23] Randall GC. pH values and blood-gas tensions in the normal piglet during the first $48 \mathrm{~h}$ of life. Biol Neonate 1972;20: 68-73.

[24] Glawischnig E, Schlerka G. Investigations on the blood gases and the acid-base-composition in piglets with hematocrit and hemoglobin determination. 1st communication: phase from parturition to the end of the 3rd day (author's transl). Dtsch Tierarztl Wochenschr 1980;87:441-3.
[25] Brenner KV, Gürtler H. Acid-base balance and lactate content in blood of newborn piglets, depending on parturition. Monatsh Veterinarmed 1977;32:850-3.

[26] Wilhelm VU, Maurer-Schweizer H, Walser K. Blood gases and acid-base equilibrium in newborn piglets after normal birth. Berl Munch Tierarztl Wochenschr 1977;90:92-5.

[27] Moon PF, Erb HN, Ludders JW, Gleed RD, Pascoe PJ. Perioperative risk factors for puppies delivered by caesarean section in the United States and Canada. J Am Anim Hosp Assoc 2000;36: 359-68.

[28] Vaillancourt C, Berger N, Boksa P. Effects of vaginal birth versus caesarean section birth with general anesthesia on blood gases and brain energy metabolism in neonatal rats. Exp Neurol 1999;160:142-50.

[29] Hall LW, Clarke KW. Veterinary anaesthesia, ninth ed., W.B. Saunders; 1991.

[30] Low JA. Intrapartum fetal asphyxia: definition, diagnosis, and classification. Am J Obstet Gynecol 1997;176:957-9.

[31] Taverne MA, Naaktgeboren C, Elsaesser F, Forsling ML, van der Weyden GC, Ellendorff F, et al. Myometrial electrical activity and plasma concentrations of progesterone, estrogens and oxytocin during late pregnancy and parturition in the miniature pig. Biol Reprod 1979;21:1125-34.

[32] Curtis SE. Responses of the piglet to perinatal stressors. J Anim Sci 1974;38:1031-6.

[33] Friendship RM, Metzger KR, Robinson NP, Doig GS. Caesarean section in the sow: a retrospective analysis of litter size and stillbirth rate. Can Vet J 1990;31:697-9.

[34] Leenhouwers JI, de Almeida Junior CA, Knol EF, van der Lende T. Progress of farrowing and early postnatal pig behavior in relation to genetic merit for pig survival. J Anim Sci 2001;79:1416-22.

[35] Taverne MA, Randall GC. Heart-rate changes and gasping during intra-partum asphyxiation of a piglet. A case report. Theriogenology 1983;19:707-11.

[36] Hoy S, Lutter C, Puppe B, Wahner M. Influence of endogenous and exogenous factors on the dynamics of rectal temperature in newborn piglets. Prakt Tierarzt 1995;76:238-49. 